\title{
Teknik Penyederhanaan untuk Menyederhanakan Teknik Resolusi
}

\author{
Djoni Dwijono \\ Teknik Informatika Universitas Kristen Duta Wacana Yogyakarta \\ Email: djoni@ukdw.ac.id
}

\begin{abstract}
Abstrak:
Teknik Resolusi sebenarnya tidak mudah dikerjakan karena teknik ini memiliki beberapa langkah-langkah yang cukup rumit dikerjakan, antara lain menjalankan strategi perlawanan, membuat bentuk normal konjungtif, lalu melakukan resolve antar klausa yang memiliki literal berpasangan secara terus menerus dengan bentuk pohon resolusi sampai diperoleh hasil terakhir berupa simbol falsum yang berarti terjadi kontradiksi, dan dari hasil berupa falsum ini dibuktikan validitas argumen tersebut.

Ekspresi logika berbentuk bentuk normal konjungtif yang panjang dan masih rumit, dapat disederhanakan dengan teknik penyederhanaan menjadi bentuk normal konjungtif yang paling sederhana dan memudahkan proses resolve antar klausa, sehingga pembuatan pohon resolusi menjadi sangat pendek, mudah dan sederhana.
\end{abstract}

Kata kunci: Teknik Resolusi, Bentuk Normal Konjungtif, Resolve, Pohon Resolusi, Teknik Penyederhanaan

\section{Pengantar}

Persoalan utama pada logika matematika ada usaha untuk membuktikan validitas argumen dengan berbagai teknik atau metode yang semakin efisien tetapi tetap andal sebagai alat pembuktian. Dari berbagai teknik tersebut kemudian dikembangkan lagi menjadi lebih sempurna dan dapat diimplementasikan ke dalam berbagai bidang, antara lain bidang ilmu elektronika dan komputer.

Selain masalah validitas, logika matematika dengan berbagai metode atau tekniknya dapat digunakan untuk membuktikan adanya konsistensi (consistency), yakni tidak dijumpai adanya kontradiksi (berlawanan) antara satu statemen dengan statemen lainnya di dalam satu argumen, atau di dalam suatu kumpulan statemen. Dalam dunia politik yang penuh dengan janji, masalah konsistensi dan kontradiksi ini terkenal dengan pameo 'esok dele, sore tempe (pagi masih berupa kedelai, sorenya sudah menjadi tempe)', yang dapat dibaca 'janji pada saat kampanye akan berbeda realisasinya pada saat sudah menjadi pejabat'. 
Pada artikel ini akan dibahas pembuktian validitas argumen dengan menggunakan teknik Resolusi. Di dalam logika proposisional, teknik resolusi sebenarnya cukup panjang dan memerlukan ketelitian yang cukup tinggi, karena teknik resolusi memerlukan beberapa tahap yang harus dijalankan agar pembuktian validitas dapat dilakukan dengan sempurna, tetapi tahap-tahap yang panjang tersebut, ada bagian yang dapat disederhanakan dan mempercepat proses pembuktian dengan catatan proses penyederhanaan sebenarnya bukan persoalan yang mudah dikerjakan.

Teknik Resolusi sangat bermanfaat pada bidang ilmu komputer terutama di bidang basisdata yang mempermasalahkan relasi antar tabel. Teknik menghubungkan antar tabel dan teknik melakukan query antar tabel dapat lebih dipermudah dengan menggunakan teknik resolusi.

\section{Teknik Resolusi}

Teknik Resolusi diperkenalkan oleh J.A. Robinson sekitar tahun 1960an. Teknik ini sebenarnya tidak dengan mudah dapat digunakan karena harus melalui beberapa tahap dan setiap tahap tersebut memerlukan pengertian-pengertian dasar dari logika matematika. Beberapa pengertian tersebut antara lain strategi perlawanan (refutation strategy), bentuk normal konjungtif (conjunctive normal form), klausa (clause) dan literal berpasangan (complementary literal).

Dari pengertian-pengertian dasar logika matematika tersebut, teknik resolusi menyusunnya secara bertahap sampai dengan proses resolve, yakni menghapus literal berpasangan yang ada pada setiap klausa untuk menghasilkan resolvent, atau klausa hasil proses resolve, dan dilakukan secara terus-menerus memakai bentuk pohon resolusi sampai menghasilkan falsum. Jika falsum diperoleh, argumen dinyatakan valid, sedangkan jika tidak menghasilkan falsum, argumen dinyatakan tidak valid.

Penjelasan dari pengertian-pengertian dasar dari logika tersebut dapat dijelaskan secara singkat berikut ini:

(1). Strategi Perlawanan, adalah teknik melakukan pembalikan dari 'premis-premis yang benar, menghasilkan kesimpulan yang benar', menjadi 'premis-premis yang benar, menghasilkan kesimpulan yang salah'. Caranya dengan memberi negasi pada kesimpulan, dan atau memberi nilai $\mathrm{F}$ pada kesimpulan. Teknik Resolusi memakai cara yang pertama yakni menegasi kesimpulan.

(2). Bentuk Normal (Normal Form) adalah ekspresi logika yang disusun sedemikian rupa sehingga hanya berisikan variabel-variabel proposisional dan atau negasinya dan dengan perangkai dasar lainnya yakni And dan Or. Tetapi jika disebut Bentuk Normal Konjungtif, maka proposisi majemuk di dalam satu kurung dengan kurung lainnya dirangkai dengan perangkai And, tetapi proposisi majemuk di dalam kurung dirangkai dengan perangkai Or. Contoh: $(\neg A \vee B \vee \neg C) \wedge(\neg B \vee C)$. Untuk membuat bentuk normal konjungtif, diperlukan hukumhukum logika proposisional dan kesamaan-kesamaan logis lainnya. Lihat pada Tabel-1 
terlampir. Bentuk normal yang lain adalah Bentuk Normal Disjungtif. Bentuk normal hanya ada dua bentuk tersebut, tak ada bentuk normal lainnya, walaupun dapat saja ekspresi logikanya hanya berisi variabel-variabel proposisional dan perangkai-perangkai dasar.

(3). Klausa adalah isi dari setiap rangkaian proposisi majemuk yang berada di dalam kurung pada bentuk normal konjungtif. Tetapi klausa dapat berupa literal yakni variabel proposisional dan atau negasinya saja, yang disebut Klausa Unit (Unit Clause). Contoh: $(\neg A \vee B \vee \neg C) \wedge \neg B$. Pada contoh ini $\neg B$ adalah klausa unit.

(4). Literal berpasangan adalah variabel proposisional dan negasinya. Contoh: $\neg A$ berpasangan dengan $A, \neg B$ berpasangan dengan $B$.

(5). Falsum $(\perp)$, sebenarnya simbol lain dari kontradiksi atau 0 , yang biasa digunakan untuk menggantikan konstanta proposisional $\mathrm{F}$ (False). Falsum diperoleh dari konjung literal berpasangan. Contoh: $A \wedge \neg A \equiv 0$, tetapi pada resolusi berasal dari literal berpasangan yang yang berupa dua klausa unit.

Berikut ini akan ditunjukkan proses penggunaan teknik Resolusi yang akan dilakukan tahap demi tahap untuk 2 soal, yang satu sederhana sedangkan lainnya soal yang relatif cukup rumit.

Contoh-1:

Buktikan validitas dari argumen yang berbentuk berikut ini:

$$
\{\mathrm{A} \rightarrow \mathrm{B}, \mathrm{B} \rightarrow \mathrm{C}\} \vdash \mathrm{A} \rightarrow \mathrm{C}
$$

Bukti:

Tahap-1: Negasikan kesimpulan dan susun menjadi ekspresi logika

$$
(A \rightarrow B) \wedge(B \rightarrow C) \wedge \neg(A \rightarrow C) \vdash \perp
$$

Tahap-2: Jadikan bentuk normal konjungtif

$$
\begin{array}{rlrl} 
& (A \rightarrow B) \wedge(B \rightarrow C) \wedge \neg(A \rightarrow C) & & \\
\equiv(\neg A \vee B) \wedge(\neg B \vee C) \wedge \neg(\neg A \vee C) & & \text { Material Implication } \\
\equiv(\neg A \vee B) \wedge(\neg B \vee C) \wedge(\neg \neg A \wedge \neg C) & & \text { De Morgan's Law } \\
\equiv(\neg A \vee B) \wedge(\neg B \vee C) \wedge A \wedge \neg C & & \text { Law of Double Negation }
\end{array}
$$

Jadi ekspresi logika tersebut sekarang menjadi:

$$
(\neg \mathrm{A} \vee \mathrm{B}) \wedge(\neg \mathrm{B} \vee \mathrm{C}) \wedge \mathrm{A} \wedge \neg \mathrm{C} \vdash \perp
$$

Tahap-3: Lakukan resolve antar klausa berbentuk pohon resolusi 


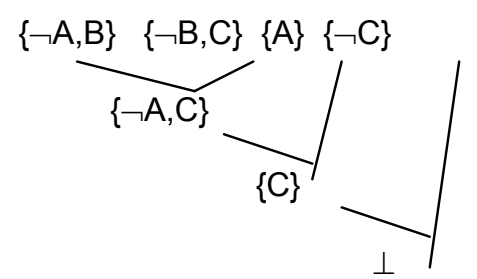

Gambar 1. Pohon Resolusi Soal-1

Dari hasil resolve tersebut ternyata menghasilkan falsum, sehingga argumen dinyatakan valid. Ekspresi logika yang dibentuk sebenarnya berasal dari argumen yang berbentuk silogisma hipotetis (hypothetical syllogism), yang jika berujud argumen dengan statemenstatemennya seperti berikut:

Jika Badu rajin belajar, maka ia tekun kuliah

Jika Badu tekun kuliah, maka ia lulus ujian

Dengan demikian, jika badu rajin belajar, maka ia lulus ujian

Contoh ekspresi logika pada soal-2 lebih rumit dari contoh soal-1, tetapi akan diberi cara mempermudah penyelesaiannya saat merubahnya menjadi bentuk normal konjungtif karena kalau dikerjakan sekaligus, akan panjang.

Contoh-2:

Buktikan validitas dari argumen yang berbentuk berikut ini:

$\{\neg \mathrm{A} \rightarrow \mathrm{B}, \neg \mathrm{A} \vee \mathrm{C} \vee \mathrm{D}, \neg \mathrm{C} \vee(\mathrm{E} \wedge \mathrm{F}),(\mathrm{F} \wedge \neg \mathrm{D}) \rightarrow \neg \mathrm{E}\} \vdash \neg \mathrm{D} \rightarrow \mathrm{B}$

Bukti:

Tahap-1: Negasikan kesimpulan dan susun menjadi ekspresi logika

$(\neg A \rightarrow B) \wedge(\neg A \vee C \vee D) \wedge(\neg C \vee(E \wedge F)) \wedge((F \wedge \neg D) \rightarrow \neg E) \wedge \neg(\neg D \rightarrow B) \vdash \perp$

Tahap-2: Jadikan bentuk normal konjungtif

Pada tahap ini setiap premis dikerjakan sendiri-sendiri dan dibentuk menjadi klausa-klausa, lalu disusun menjadi bentuk normal konjungtif

Premis-1: $\neg A \rightarrow B \equiv \neg \neg A \vee B \equiv A \vee B$

Premis-2: $\neg \mathrm{A} \vee \mathrm{C} \vee \mathrm{D}$

Premis-3: $\neg \mathrm{C} \vee(E \wedge F) \equiv(\neg C \vee E) \wedge(\neg C \vee F)$

Premis-4: $(F \wedge \neg D) \rightarrow \neg E \equiv \neg(F \wedge \neg D) \vee \neg E \equiv \neg F \vee \neg \neg D \vee \neg E \equiv \neg F \vee D \vee \neg E$

Kesimpulan : $\neg(\neg \mathrm{D} \rightarrow \mathrm{B}) \equiv \neg(\neg \neg \mathrm{D} \vee \mathrm{B}) \equiv \neg \neg \neg \mathrm{D} \wedge \neg \mathrm{B} \equiv \neg \mathrm{D} \wedge \neg \mathrm{B}$

Jadi bentuk normal konjungtif sebagai berikut:

$(A \vee B) \wedge(\neg A \vee C \vee D) \wedge(\neg C \vee E) \wedge(\neg C \vee F) \wedge(\neg F \vee D \vee \neg E) \wedge \neg D \wedge \neg B$

Tahap-3: Lakukan resolve antar klausa berbentuk pohon resolusi 


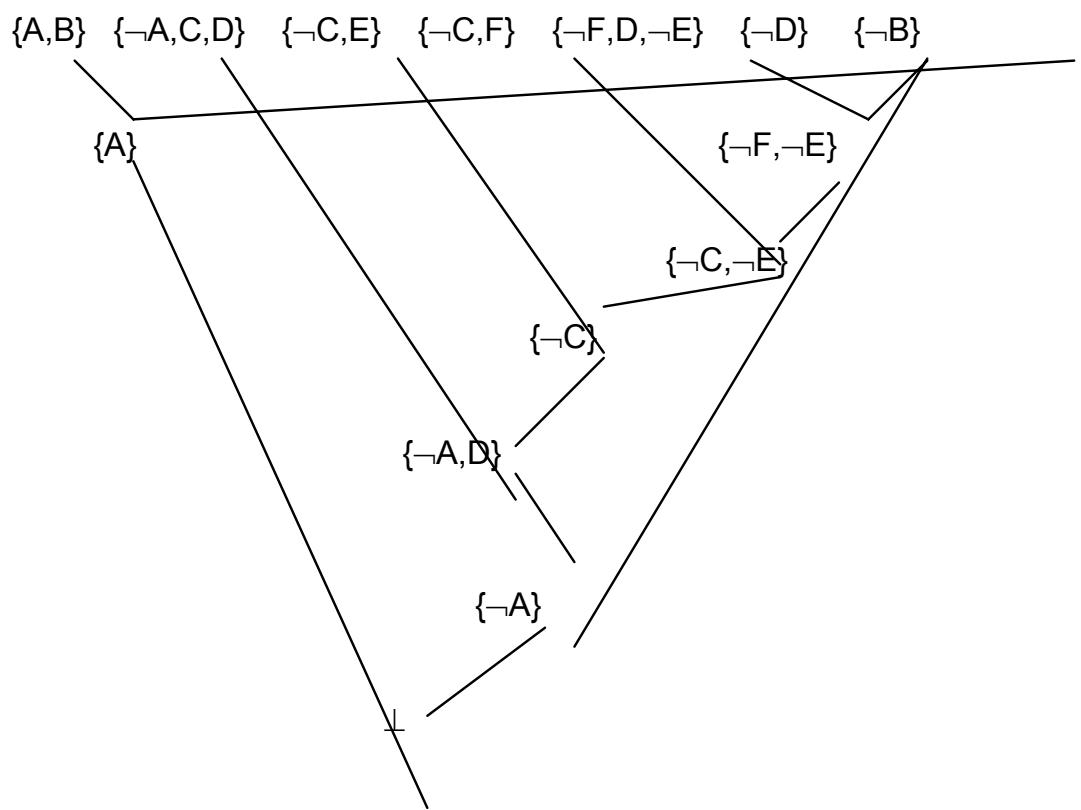

Gambar 2. Pohon resolusi soal-2

Terlihat penyelesaian soal-2 cukup rumit, dan tampak pada pohon resolusinya. Proses resolve terjadi berulang-ulang sampai menghasilkan falsum, dan tentunya hal ini tidak sederhana lagi karena dapat saja klausa dipergunakan berulang kali, tetapi tetap tidak boleh menyalahi aturan saat melakukan resolve.

Dalam penyelesaian soal yang lain, dapat saja terjadi proses resolve dilakukan pada klausa-klausa hasil resolve (resolvent). Tetapi perlu diperhatikan, pada proses resolve dapat saja antar klausa memiliki lebih dari satu literal berpasangan. Jika dijumpai kasus semacam ini, harus memilih satu literal berpasangan saja yang akan dihapus. Contoh: $\{A, \neg B, C\}$ dan $\{\neg A$, B\}. Hasil resolve adalah $\{\neg B, B, C\}$ atau $\{\neg A, A, C\}$. Tidak diijinkan menghapus lebih dari dua literal berpasangan sekaligus. Tetapi jika literal sama, boleh disederhanakan menjadi satu saja.

Teknik Resolusi sebenarnya luwes saat digunakan, karena setiap penyelesaian dapat berbeda-beda karena klausa-klausa yang dipilih untuk dilakukan resolve dapat berbeda, sehingga pohon resolusi yang dibentuk juga berbeda.

\section{Teknik Penyederhanaan}

Teknik penyederhanaan (simplifying) memerlukan hukum-hukum logika proposisional dan kesamaan-kesamaan logis lainnya yang tercantum pada Tabel-1 terlampir. Teknik penyederhanaan sebenarnya sederhana saja karena teknik ini berusaha menyederhanakan suatu bentuk ekspresi logika yang rumit menjadi suatu bentuk ekspresi logika yang sederhana. 
Sebagai contoh adalah persoalan berikut:

Sederhanakan: $\neg \mathrm{A} \rightarrow \neg(\mathrm{A} \rightarrow \neg \mathrm{B})$

Jawaban:

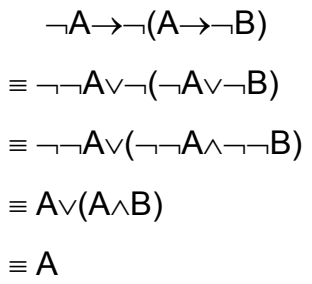

Material Implication

De Morgan's Law

Law of Double Negation

Absorption Law

Ternyata dari ekspresi logika yang disederhanakan tersebut, hanya tertinggal variabel proposisional A saja, dan variabel proposisional B hilang dalam proses penyederhanaan. Mungkin hal ini terasa aneh, tetapi inilah yang disebut penyederhanaan.

Dengan teknik penyederhanaan mungkin saja dapat menghasilkan bentuk yang sangat sederhana dari suatu ekspresi logika yang terlihat sangat rumit dengan begitu banyak variabel proposisional dan proposisi-proposisi majemuk yang membentuk ekspresi logika tersebut. Teknik penyederhanaan juga dapat digunakan untuk pembuktian validitas argumen. Jika menghasilkan 1 atau $\mathrm{T}$ (true) disebut tautologi atau argumen dinyatakan tidak valid, jika menghasilkan 0 atau $\mathrm{F}$, atau menghasilkan tidak 1 atau tidak 0 disebut contingent, argumen dinyatakan tidak valid.

Teknik penyederhanaan juga digunakan secara intensif untuk menyederhanakan rancangan sirkit (circuit) dari alat-alat elektronik masa sekarang. Metode penyederhanaan sirkit dalam bidang elektronika yang terkenal adalah Metode Karnaugh (Karnaugh Map) dan Metode Quine-McCluskey.

\section{Implementasi Teknik Penyederhanaan pada Teknik Resolusi}

Teknik penyederhanaan pada teknik resolusi dilakukan pada saat membentuk ekspresi logika menjadi bentuk normal konjungtif. Bentuk normal konjungtif lebih disederhanakan lagi menjadi bentuk normal konjungtif yang paling sederhana.

$$
\begin{aligned}
& (\neg A \vee B) \wedge(\neg B \vee C) \wedge A \wedge \neg C \\
\equiv & A \wedge(\neg A \vee B) \wedge(\neg B \vee C) \wedge \neg C \\
\equiv & (A \wedge(\neg A \vee B)) \wedge((\neg B \vee C) \wedge \neg C) \\
\equiv & (A \wedge B) \wedge(\neg B \wedge \neg C) \\
\equiv & A \wedge B \wedge \neg B \wedge \neg C
\end{aligned}
$$

Commutative Law

Tambah kurung biasa

Absorption Law

Hapus kurung biasa 
Dengan cepat pohon resolusi dapat dibuat seperti berikut:

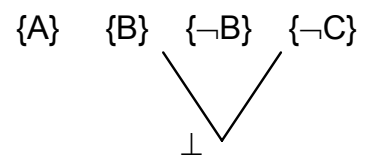

Gambar 3. Pohon Resolusi Soal-1 sesudah disederhanakan

$$
\begin{aligned}
& (A \vee B) \wedge(\neg A \vee C \vee D) \wedge(\neg C \vee E) \wedge(\neg C \vee F) \wedge(\neg F \vee D \vee \neg E) \wedge \neg D \wedge \neg B \\
\equiv & (\neg B \wedge(B \vee A)) \wedge(((\neg A \vee C) \vee D) \wedge \neg D) \wedge(\neg C \vee E) \wedge(\neg C \vee F) \wedge(\neg F \vee D \vee \neg E) \\
\equiv & \neg B \wedge A \wedge(\neg A \vee C) \wedge \neg D \wedge(\neg C \vee E) \wedge(\neg C \vee F) \wedge(\neg F \vee D \vee \neg E) \\
\equiv & \neg \wedge(A \wedge(\neg A \vee C)) \wedge(\neg C \vee E) \wedge(\neg C \vee F) \wedge(\neg D \wedge(D \vee(\neg F \vee \neg E))) \\
\equiv & B \wedge A \wedge C \wedge(\neg C \vee E) \wedge(\neg C \vee F) \wedge \neg D \wedge(\neg F \vee \neg E) \\
\equiv & B B \wedge A \wedge(C \wedge(\neg C \vee E)) \wedge(\neg C \vee F) \wedge \neg D \wedge(\neg F \vee \neg E) \\
\equiv & B \wedge A \wedge C \wedge E \wedge(\neg C \vee F) \wedge \neg D \wedge(\neg F \vee \neg E) \\
\equiv & \neg B \wedge A \wedge C \wedge(\neg C \vee F) \wedge \neg D \wedge((\neg F \vee \neg E) \wedge E) \\
\equiv & B \wedge A \wedge C \wedge F \wedge \neg D \wedge \neg F \wedge E
\end{aligned}
$$

Dengan cepat pohon resolusi dapat dibuat seperti berikut:

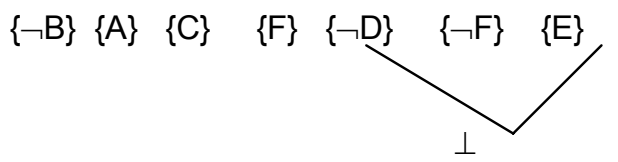

Gambar 4. Pohon Resolusi Soal-2 sesudah disederhanakan

Jelas terlihat teknik Resolusi yang cukup rumit seperti tampak pada Gambar 2 dapat disederhanakan menjadi bentuk pohon resolusi yang sangat sederhana dan tampak pada Gambar 4. Selain sederhana, jelas bahwa hasilnya dapat dipertanggungjawabkan karena proses penyederhanaan tidak mengubah apapun dari teknik Resolusi, kecuali hanya membentuk bentuk normal konjungtif yang paling sederhana, dan tetap memenuhi pengertian bentuk normal konjungtif. 


\section{Kesimpulan}

Beberapa kesimpulan yang diperoleh adalah:

(1). Teknik penyederhanaan dapat digunakan pada teknik Resolusi pada saat menyederhanakan proses membentuk bentuk normal konjungtif menjadi bentuk normal konjungtif yang paling sederhana

(2). Proses resolve dan pembuatan pohon resolusi dapat diperpendek dan dipercepat karena bentuknya sudah sangat sederhana

(3). Tahapan proses pembuktian validitas argumen dengan Teknik Resolusi tidak berubah karena hanya menyederhanakan bentuk normal konjungtif saja, tidak merubah tahapan proses

\section{Daftar Pustaka}

[1] Copi, Irving M. (1979). Symbolic Logic. $5^{\text {th }}$ Edition. MacMillan Publishing Company

[2] Copi, Irving M. dan Cohen, Carl. (2009). Introduction to Logic. $13^{\text {th }}$ Edition. Pearson Prentice Hall, Upper Saddle River, New Jersey

[3] Grassman, Winfried Karl dan Tremblay, Jean Paul. (1996). Logic and Discrete Mathematics - A Computer Science Approach. Prentice Hall International Editions, Upper Saddle River: New Jersey

[4] Kelly, John J. (1997). The Essence of Logic. $1^{\text {st }}$ Publication, Prentice Hall Europe 
Lampiran:

Tabel-1 : Daftar Kesamaan Logis [Hukum-hukum Logika Proposisional]

\begin{tabular}{|l|l|}
\hline \multicolumn{1}{|c|}{ KESAMAAN LOGIS } & \multicolumn{1}{|c|}{ NAMA } \\
\hline$A \wedge 1 \equiv A$ & Identity Laws \\
$A \vee 0 \equiv A$ & Identity Laws \\
\hline$A \wedge 0 \equiv 0$ & Dominition Laws \\
$A \vee 1 \equiv 1$ & Dominition Laws \\
\hline$A \wedge \neg A \equiv 0$ & Law of Contradiction \\
$A \vee \neg A \equiv 1$ & Excluded Middle Law \\
\hline$A \wedge A \equiv A$ & Idempotent Laws \\
$A \vee A \equiv A$ & Idempotent Laws \\
\hline$\neg \neg A \equiv A$ & Law of Double Negation \\
\hline$A \wedge B \equiv B \wedge A$ & Commutative Laws \\
$A \vee B \equiv B \vee A$ & Commutative Laws \\
\hline$(A \wedge B) \wedge C \equiv A \wedge(B \wedge C)$ & Assosiative Laws \\
$(A \vee B) \vee C \equiv A \vee(B \vee C)$ & Assosiative Laws \\
\hline$A \wedge(B \vee C) \equiv(A \wedge B) \vee(A \wedge C)$ & Distributive Laws \\
$A \vee(B \wedge C) \equiv(A \vee B) \wedge(A \vee C)$ & Distributive Laws \\
\hline$A \wedge(A \vee B) \equiv A$ & Absorption Laws \\
$A \vee(A \wedge B) \equiv A$ & Absorption Laws \\
\hline$A \wedge(\neg A \vee B) \equiv A \wedge B$ & Absorption Laws \\
$A \vee(\neg A \wedge B) \equiv A \vee B$ & Absorption Laws \\
\hline$(A \wedge B) \vee(A \wedge \neg B) \equiv A$ & Absorption Laws \\
$(A \vee B) \wedge(A \vee \neg B) \equiv A$ & Absorption Laws \\
\hline$(A \wedge B) \vee(\neg A \wedge B) \equiv B$ & Absorption Laws \\
$(A \vee B) \wedge(\neg A \vee B) \equiv B$ & Absorption Laws \\
\hline$\neg(A \wedge B) \equiv \neg A \vee \neg B$ & De Morgan's Laws \\
$\neg(A \vee B) \equiv \neg A \wedge \neg B$ & De Morgan's Laws \\
\hline$A \wedge B \equiv \neg(\neg A \vee \neg B)$ & De Morgan's Laws \\
$A \vee B \equiv \neg(\neg A \wedge \neg B)$ & De Morgan's Laws \\
\hline$A \rightarrow B \equiv \neg A \vee B$ & Material Implication \\
$\equiv \neg(A \wedge \neg B)$ & \\
\hline$A \wedge B \equiv(A \wedge B) \vee(\neg A \wedge \neg B)$ & Material Equivalence \\
$\equiv(A \rightarrow B) \wedge(B \rightarrow A)$ & \\
$\equiv(\neg A \vee B) \wedge(\neg B \vee A)$ & \\
\hline$(A \wedge B) \rightarrow C \equiv(\neg(\neg A \vee B) \vee \neg(\neg B \vee A))$ & Transposition \\
\hline$A \rightarrow B \equiv \neg B \rightarrow \neg A$ & \\
\hline
\end{tabular}

